\title{
Underwater endoscopic mucosal resection of adenomas and colorectal serrated lesions: a prospective clinical study
}

\author{
Pedro Bothrel Nogueira a, Walton Albuquerque a, Ricardo Castejon Nascimento ${ }^{a}$, \\ Bruna Santos Marianellia, Frederico Fonseca Campos ${ }^{a}$, Rodrigo Albuquerque Carreiro ${ }^{a}$, \\ Renata Figueiredo Rocha ${ }^{a}$, Roberto Motta Pereira ${ }^{a}$, Vitor Nunes Arantes ${ }^{b}$ \\ Hospital Madre Teresa; Alfa Institute of Gastroenterology, Belo Horizonte, Minas Gerais, Brazil
}

\section{Abstract}

\begin{abstract}
Background Underwater endoscopic mucosal resection (UEMR) without submucosal injection has been described as an alternative technique to the endoscopic resection of adenomas and colorectal serrated lesions. We aimed to assess the feasibility, safety, and efficacy of UEMR in a Brazilian setting.
\end{abstract}

Methods This was a prospective observational study of consecutive patients who underwent UEMR between January and July 2019, in a single tertiary care center. Inclusion criteria were lesions without endoscopic stigmata of deep submucosal invasion in patients referred for endoscopic resection of colorectal adenomas, and serrated lesions detected in a previous colonoscopy. The following features were assessed: complete resection rate, en bloc resection rate, resection time, adverse events, and resection infeasibility.

Results A total of 36 patients underwent UEMR for 51 colorectal lesions. The mean/median lesion size was $16.24 / 13 \mathrm{~mm}$ and the mean/median resection time was $16.97 / 9.19 \mathrm{~min}$. Histopathology revealed the following: tubular adenoma (43.1\%), tubulovillous adenoma (13.7\%), serrated lesions (41.2\%), and intramucosal adenocarcinoma (2\%). Complete resection was achieved in $86.3 \%$ of cases; $52.9 \%$ of the lesions were removed en bloc, while $47.1 \%$ were resected in a piecemeal fashion. UEMR was feasible in $96.1 \%$ of cases and failed on 2 occasions, requiring conversion to standard endoscopic mucosal resection. Minor intraoperative bleeding occurred in 5 patients $(9.8 \%)$ and only 1 presented with delayed bleeding (2\%), all controlled endoscopically.

Conclusion UEMR for removal of adenomas and colorectal serrated lesions was demonstrated to be feasible, safe and effective.

Keywords Underwater endoscopic mucosal resection, colorectal adenomas, colorectal serrated lesions, colonoscopy

Ann Gastroenterol 2021; 34 (X): 1-7
aDepartment of Digestive Endoscopy, Hospital Madre Teresa (Pedro Bothrel Nogueira, Walton Albuquerque, Ricardo Castejon Nascimento, Bruna Santos Marianelli, Frederico Fonseca Campos, Rodrigo Albuquerque Carreiro, Renata Figueiredo Rocha, Roberto Motta Pereira); ${ }^{\mathrm{b}}$ Faculdade de Medicina da Universidade Federal de Minas Gerais, Alfa Institute of Gastroenterolgy (Vitor Nunes Arantes), Belo Horizonte, Minas Gerais, Brazil

\section{Conflict of Interest: None}

Correspondence to: Pedro Bothrel Nogueira, Rua Paracatú 705, apto 1603, Barro Preto, Belo Horizonte, Minas Gerais, Brazil, e-mail: pedro1612@hotmail.com

Received 18 February 2020; accepted 18 February 2021; published online 3 April 2021

DOI: https://doi.org/10.20524/aog.2021.0625

\section{Introduction}

Detection and endoscopic resection of colorectal lesions such as adenomas and serrated polyps are well-established strategies for the prevention of colorectal carcinoma (CRC) [1,2]. The European Society of Gastrointestinal Endoscopy strongly recommends, with a high level of evidence, that all colorectal polyps should be resected, except for diminutive rectosigmoid lesions that are reliably considered hyperplastic [3]. Endoscopic removal of adenomas, even from tiny lesions, has been widely recommended worldwide to reduce the incidence and mortality associated with CRC [4]. More recently, serrated lesions, particularly from the right colon, formerly considered hyperplastic lesions, have been 
demonstrated to present a new oncogenic pathway and should also be treated similarly to adenomas [5].

Endoscopic mucosal resection (EMR) using flexible endoscopes was first described in the 1970s and the procedure remains essentially unchanged [6-8]. During EMR, a solution is injected into the submucosal space through a needle catheter to create a cushion between the muscularis propria and the lesion, which allows for a safe and effective resection using electrosurgical energy. This technique is widely used and allows the removal of colorectal adenomas of varying sizes [6]. Underwater EMR (UEMR) is a technique first described by Binmoeller et al [9] and subsequently reported in other studies, which confirmed it was easy to learn, safe and effective [6,9-18]. In contrast to EMR, the intestinal lumen is filled with water instead of air/ $\mathrm{CO}_{2}$, and no submucosal injection is added. Conceivably, submucosal injection reduces the risk of iatrogenic perforation and thermal injury to the deeper tissue layers. However, on some occasions it can paradoxically make capture of flat lesions difficult, increase tension in the intestinal wall secondary to air insufflation and decrease the space within the organ lumen, limiting the working area. Furthermore, in lesions with fibrosis submucosal injection is followed by a non-lifting sign, which prevents resection by this technique [9]. In addition, there is concern about the risk of neoplastic cell implantation to deeper layers when injecting through the polyp [19], although this issue is debatable and still unproven.

In clinical practice, UEMR is not yet disseminated, particularly in Latin American countries, where the literature related to the topic is still scarce. Thus, this prospective study aimed to assess the feasibility, safety and efficacy of the UEMR technique for the resection of adenomas and colorectal serrated lesions in a Brazilian setting.

\section{Patients and methods}

\section{Study population and design}

This was a prospective case series of consecutive patients who underwent UEMR for resection of adenomas and colorectal serrated lesions, detected in a previous colonoscopic examination, and conducted in a single tertiary care center (Hospital Madre Teresa, Belo Horizonte, Brazil) between January and July 2019. Inclusion criteria were lesions without endoscopic stigmata of deep submucosal invasion, $\geq 5 \mathrm{~mm}$ in length, and considered suitable for endoscopic resection. Lesions that were not previously detected, but were identified during the study procedure and fulfilled the criteria, were also included. Exclusion criteria were lesions that showed signs of malignant degeneration or deep submucosal invasion (depression, ulceration, friability, bleeding, induration, Kudo pit pattern V); pedunculated polyps; patients with familial polyposis syndromes; those with contraindications (e.g., coagulation disorders and other comorbidities) for endoscopic resection by any technique; and patients who did not agree to participate in the research.
All patients provided written informed consent after receiving an explanation of the endoscopic procedures and study participation. This study was performed in accordance with the principles of the Declaration of Helsinki. Approval was granted by the Institutional Review Board and the Ethics and Research Committee of Hospital Madre Teresa. Trial Registration Number: RBR-262j28.

\section{UEMR procedure}

Colonoscopies were performed by 2 interventional endoscopists with experience in EMR, each having performed more than 1000 EMRs. All patients were evaluated by highdefinition colonoscopes (530, 590 and 600 series; Fujifilm Corporation, Saitama-Shi, Saitama, Japan). $\mathrm{CO}_{2}$ insufflation was used for all procedures (GW-100; Fujifilm Corporation Saitama-Shi, Saitama, Japan).

Target-lesion macroscopic features were studied with $0.4 \%$ indigo-carmine chromoendoscopy and digital chromoendoscopy with Fuji Intelligent Color Enhancement. The lesion's size was estimated by visual comparison with the diameter of the opened snare before water instillation. Captivator $^{\circledR}$ snares (Boston Scientific Corporation, Marlborough, USA) were used in association with an electrocautery microprocessor (Endocut, 25W, effect 4, ERBE VIO 300S; ERBE Elektromedizim, Tübingen, Germany). Paris and Kudo pit pattern endoscopic classifications were used to characterize the lesions $[20,21]$.

After macroscopic assessment of a lesion, intraluminal air was evacuated and approximately $500-1000 \mathrm{~mL}$ of sterile water at room temperature was infused until the lumen was completely filled. The resection started at the lesion's distal margin, opening the snare and positioning it in order to include a rim of normal mucosa inside, and torque was applied to the colonoscope to maximize its capture. An en bloc tumor resection was always attempted, and when the lesion size was considered unsuitable for en bloc resection the tumor was resected in a piecemeal fashion. The mucosal defect and the resection margins were carefully examined post-procedure and any residual lesion was eradicated by either a snare or a biopsy forceps. Immediate bleedings were controlled with available endoscopic methods. Biopsies of the mucosal defect margins were obtained to evaluate free pathologic margins, in a number that depended on the size of the lesions. All collected material was properly stored in bottles with $10 \%$ formaldehyde, labeled and sent for histopathological analysis. The resection area was closed with endoscopic clips (Olympus Medical System Corporation, Tokyo, Japan), based on the Sydney classification [22] and at the discretion of the endoscopist. Fig. 1 is illustrative of the UEMR procedure.

\section{Outcomes}

The following outcomes were assessed: complete resection rate, en bloc resection rate, resection time, adverse events, 

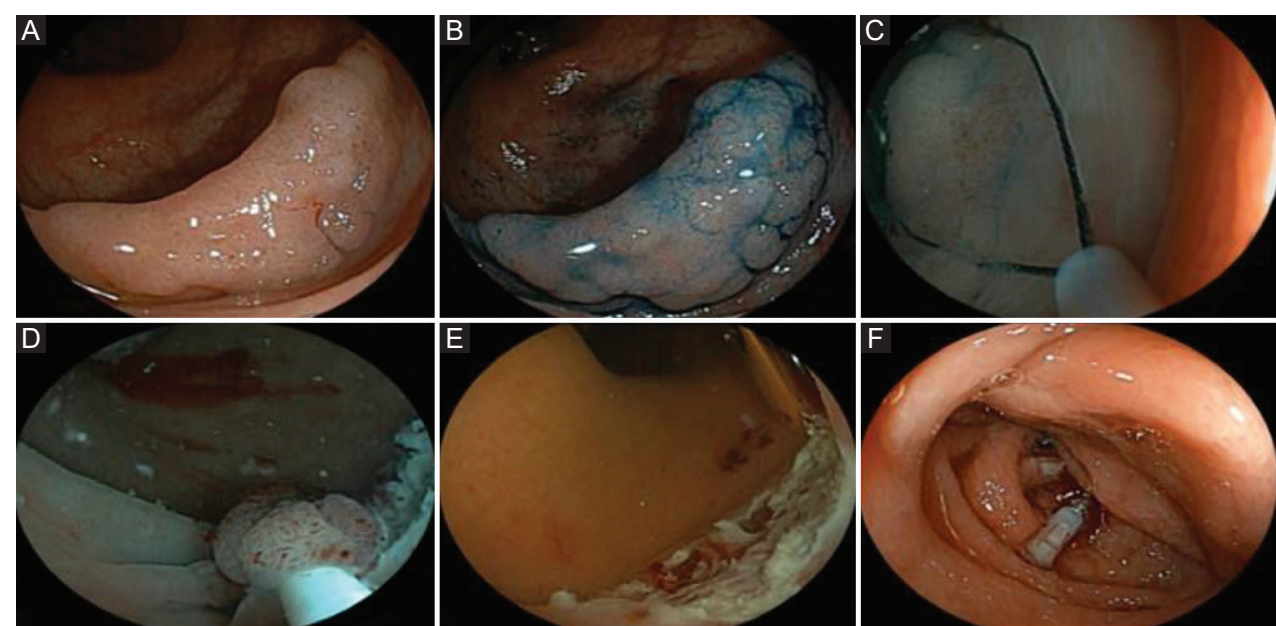

Figure 1 Adenoma with laterally spreading component along the ascending colon ( $20 \mathrm{~mm}$ in size). (A) Before underwater endoscopic mucosal resection (UEMR). (B) Chromoendoscopy with indigo-carmine. (C, D) Piecemeal UEMR. (E) Mucosal defect after piecemeal UEMR. (F) Closure of the mucosal defect and hemostasis with endoscopic clips

and resection failure due to technical difficulties. Complete resection was defined as the absence of macroscopically visible lesion fragments by the endoscopist when evaluating the defect, plus negative biopsies from the edges of the postresection area. En bloc resection was defined as complete endoscopic removal of the entire lesion in one piece. The resection time was recorded from the instillation of water into the intestinal lumen until the ending of the resection, including the use of endoscopic clips when needed. The adverse events identified were: intraoperative bleeding (occurring during the procedure), early bleeding (within $24 \mathrm{~h}$ ), or delayed bleeding (after $24 \mathrm{~h}$, within 30 days) requiring hemostatic endoscopic treatment; post-polypectomy syndrome; and intestinal perforation, as defined by evidence of air or luminal contents outside the gastrointestinal tract [23], either endoscopically and/or through radiological examinations. UEMR was considered to have failed when tumor snare capture was not feasible, requiring conversion to EMR.

\section{Follow up}

The follow up of patients was carried out by telephone 30 days after the procedure, interrogating about possible complications/adverse events. Colonoscopic first control within 3-6 months was proposed for patients with residual lesions. We considered residual lesions those whose postresection margin biopsies were positive for adenoma/serrated lesion.

\section{Statistical analysis}

The information was analyzed using descriptive statistics techniques, with the construction of graphs, tables and the calculation of measures such as means, medians, standard deviations and percentages in order to synthesize the collected data.

\section{Results}

From January to July 2019, 39 patients with 54 colorectal lesions were referred to endoscopic resection. Three patients were excluded because of endoscopic signs of deep submucosal invasion $(n=2)$ and refusal to sign the consent form $(n=1)$. Thus, 36 patients $(58.5 \%$ female) with 51 colorectal lesions underwent UEMR and entered the study (Fig. 2).

Table 1 presents the clinico-pathological characteristics of the population. The average age was 63 years, ranging from 33-86 years, and the mean/median size of the lesions was 16.24/13 mm (range: 7-60 mm). Regarding the location, 38 $(74.5 \%)$ lesions were found in the right colon, 10 (19.6\%) in the left colon, and $3(5.8 \%)$ in the rectum. Histopathological evaluation revealed $43.1 \%$ tubular adenomas, $13.7 \%$ tubulovillous adenomas, $41.2 \%$ serrated lesions (of these $25.5 \%$ were hyperplastic polyps, $11.7 \%$ were sessile serrated polyp and $4 \%$ were traditional serrated adenomas), and $2 \%$ intramucosal adenocarcinoma.

Complete resection was achieved in 44 of 51 lesions (86.3\%), with 27 lesions removed en bloc (52.9\%) and 24 resected in a piecemeal fashion $(47.1 \%)$. When we considered only lesions $\geq 20 \mathrm{~mm}$, we obtained an en bloc resection rate of $23.5 \%$, which reached up to $47 \%$ for lesions $\geq 15 \mathrm{~mm}$. During the study 27 lesions $<15 \mathrm{~mm}$ were resected, 15 (55.5\%) in the first half of the study, and $12(44.4 \%)$ in the second half. All 15 lesions from the first half were removed en bloc. Of the 12 lesions removed during the second half of the study, 5 were resected in a piecemeal manner.

UEMR failed in 2 lesions (3.9\%), requiring conversion to standard EMR. Endoscopic resection was accomplished 
Table 1 Characteristics of patients and endoscopic findings ( $N=36$ patients)

\begin{tabular}{|c|c|}
\hline Characteristics & Value \\
\hline Female, no. (\%) & $21(58.3)$ \\
\hline Mean age, years & 63 \\
\hline Total no. of lesions & 51 \\
\hline $\begin{array}{l}\text { Lesion size, } \mathrm{mm} \\
\text { Mean } \\
\text { Median }\end{array}$ & $\begin{array}{c}16.24 \\
13\end{array}$ \\
\hline $\begin{array}{l}\text { Size by ranges, no. (\%) } \\
5-9 \mathrm{~mm} \\
10-15 \mathrm{~mm} \\
16-20 \mathrm{~mm} \\
>20 \mathrm{~mm}\end{array}$ & $\begin{array}{c}8(15.7) \\
30(58.8) \\
5(9.8) \\
8(15.7)\end{array}$ \\
\hline $\begin{array}{l}\text { Lesion location by segment, no. (\%) } \\
\text { Right colon (cecum to transverse colon) } \\
\text { Left colon (splenic flexure to sigmoid colon) } \\
\text { Rectum }\end{array}$ & $\begin{array}{c}38(74.5) \\
10(19.6) \\
3(5.8)\end{array}$ \\
\hline $\begin{array}{l}\text { Lesion location, no. }(\%) \\
\text { Cecum } \\
\text { Ileocecal valve } \\
\text { Ascending colon } \\
\text { Hepatic flexure } \\
\text { Transverse colon } \\
\text { Splenic flexure } \\
\text { Descending colon } \\
\text { Sigmoid colon } \\
\text { Rectum }\end{array}$ & $\begin{array}{c}7(13.5) \\
1(2.0) \\
17(33.3) \\
2(3.9) \\
11(21.6) \\
1(2.0) \\
5(9.8) \\
4(7.8) \\
3(5.8)\end{array}$ \\
\hline $\begin{array}{l}\text { Morphology, Paris classification, no. (\%) } \\
\text { 0-Is } \\
0 \text {-IIa } \\
\text { LST-G (0-IIa) } \\
\text { LST-G mixed (0-IIa+Is) } \\
\text { LST-NG (0-IIa) }\end{array}$ & $\begin{array}{c}7(13.2) \\
13(25.5) \\
15(29.4) \\
2(3.9) \\
14(27.5)\end{array}$ \\
\hline $\begin{array}{l}\text { Histology, no. (\%) } \\
\text { Tubular adenoma } \\
\text { Tubulovillous adenoma } \\
\text { Serrated lesions } \\
\text { Traditional serrated adenoma } \\
\text { Sessile serrated polyp } \\
\text { Hyperplastic polyp }\end{array}$ & $\begin{array}{l}22(43.1) \\
7(13.7) \\
21(41.2) \\
2(4.0) \\
6(11.7) \\
13(25.5)\end{array}$ \\
\hline Complete resection rate, no. (\%) & $44(86.3)$ \\
\hline En bloc resection rate, no (\%) & $27(52.9)$ \\
\hline $\begin{array}{l}\text { Resection time, min } \\
\text { Mean } \\
\text { Median }\end{array}$ & $\begin{array}{c}16.97 \\
9.19\end{array}$ \\
\hline $\begin{array}{l}\text { Adverse events, no. (\%) } \\
\text { Hemorrhage } \\
\text { Intraoperative bleeding } \\
\text { Early bleeding } \\
\text { Delayed bleeding } \\
\text { Post-polypectomy syndrome } \\
\text { Perforation }\end{array}$ & $\begin{array}{l}6(11.8) \\
5(9.8) \\
0(0.0) \\
1(2.0) \\
0(0.0) \\
0(0.0)\end{array}$ \\
\hline
\end{tabular}

successfully in $96.1 \%$ of cases. The mean/median resection time was $16.97 / 9.19 \mathrm{~min}$, respectively (range: $2.57-105 \mathrm{~min}$ ). Only 1 patient presented delayed bleeding (2\%), which occurred on the $6^{\text {th }}$ day after resection and was treated with endoscopic clips.

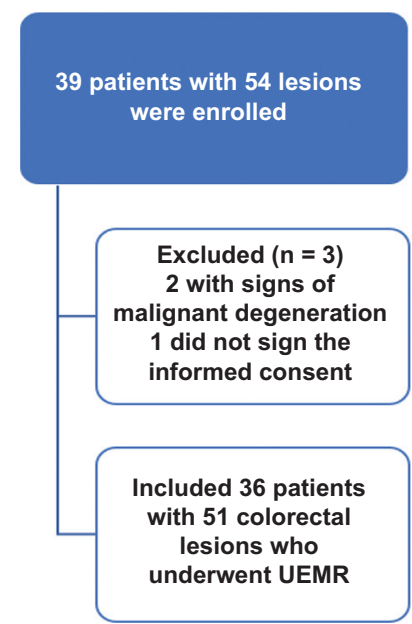

Figure 2 Enrolment of patients

UEMR, underwater endoscopic mucosal resection

Minor intraoperative bleeding occurred in 5 patients $(9.8 \%)$ and was also controlled endoscopically (4 with endoscopic clips and 1 using the snare tip associated with electrocautery soft-coagulation). Blood transfusions were not necessary in any of the cases. There was no intestinal perforation or postpolypectomy syndrome.

Of the 49 lesions treated exclusively by UEMR, 5 (10.2\%) presented residual lesions disclosed on histology of a biopsy of the resection margins; therefore, a surveillance colonoscopy was proposed. Follow-up colonoscopy ranged from 3-6 months and was undertaken in only 2 cases, one presenting scar without residual lesion and the other presenting a polypoid lesion upon the scar that required rescue UEMR, with histopathology confirming a hyperplastic polyp.

\section{Discussion}

The role of standard EMR with submucosal injection is already well established for removal of colorectal lesions. UEMR without injection of solution into the submucosa has been used as an alternative method to standard EMR, and some series have demonstrated its safety and clinical effectiveness [6,9-18]. Water submersion allows a greater area of mucous surface to be captured inside the open snare, as there is less distension of the intestinal lumen as well as an apparent contraction and reduction in the diameter of the lesion upon the mucosa, and as a consequence offers greater potential for en bloc resection [24]. Furthermore, water submersion permits the following: a better visualization of margins via the optical effect of a natural "zoom" provided by the refraction of water [25]; reduction of wall damage induced by a diathermicsnare secondary to the heat-sinkeffect of water [26]; better identification of specific bleeding points [27]; cost reduction, since it is not necessary to use a solution and needle for injection; and according to some authors, a reduction in 
the procedure time $[13,18]$. In addition, UEMR may be useful in challenging scenarios, such as recurrent lesions [15], and lesions difficult to access [28].

To our knowledge, this is one of the first studies so far to report the use of UEMR in Brazil, since Chaves et al demonstrated its feasibility for resection of sessile serrated adenomas [29] and for difficult colorectal polyps [30] in previous case series. Our data show that UEMR was endoscopically successful in $96.1 \%$ of cases, and on only 2 occasions was conversion to EMR using submucosal injection necessary. In the first case, the lesion was in the sigmoid colon and the water did not remain in the lumen even after the patient's position was changed. This failure may have been related to the learning curve effect. In addition, Yamashina et al [31] reported that air remaining inside part of the lumen before water infusion can create a pressure gradient and push water away from the lesion; we think this may also have occurred in this particular case. The second case was a $35 \mathrm{~mm}$ lesion located in the hepatic flexure, over and behind a fold, which prevented good access for adequate snaring and ultimately required submucosal injection to improve the exposure. Siau et al [16] also reported that UEMR may not be feasible in special circumstances, such as recurrent polyps, depressed (0-IIc) lesions and larger lesions with suboptimal access.

In the present case series, we obtained a complete resection rate of $86.3 \%$ and an en bloc resection rate of $52.9 \%$, accomplished in an average time of $16.97 \mathrm{~min}$. These findings corroborate the results of a recent systematic review, which included 10 prospective and retrospective studies [32] and demonstrated a complete resection rate of $96.9 \%$ and en bloc resection rate of $57.1 \%$ using UEMR. In the only randomized controlled study comparing UEMR with EMR [31] for lesions of intermediate size (10-20 mm), with 108 lesions in the UEMR group and 102 lesions in the EMR group, the R0 resection rate was $69 \%$ for UEMR versus 50\% for EMR, while en bloc resection was achieved in $89 \%$ with UEMR and 75\% with EMR, showing that UEMR was superior as regards both en bloc and R0 resection rates for intermediate-sized lesions and hence establishing the clinical benefit of the technique in this subgroup.

It is important to note that lesion size affects the en bloc resection rate, especially for lesions over $20 \mathrm{~mm}$ [16]. Considering only lesions $\geq 20 \mathrm{~mm}$, we obtained an en bloc resection rate of $23.5 \%$, while for lesions $\geq 15 \mathrm{~mm}$ this value rose to $47 \%$. We did not observe an improvement in the en bloc resection rate for lesions $<15 \mathrm{~mm}$ in diameter in the second half of the study as expected, perhaps because the endoscopists were already experienced and had already passed the learning curve. Some authors advocate that UEMR has a greater potential for en bloc resection as compared to EMR, particularly due to the "effect of tumor size reduction" induced by water immersion [15,24,31], and that could lead to lower rates of local recurrence, which typically range from $14-55 \%$ after piecemeal EMR [15]. In the review by Spadaccini et al [32], a recurrence rate of $8.8 \%$ was identified using UEMR, while $13.8 \%$ was reported by Hassan et al [33] using conventional techniques, although the median polyp size in those 2 studies were $33 \mathrm{~mm}$ and $23 \mathrm{~mm}$ respectively, which may affect this analysis. In our study, we had 5 patients $(10.2 \%)$ with residual lesions and only 2 of them underwent a surveillance colonoscopy; thus, we do not have sufficient data to adequately analyze the recurrence or residual lesion rate. Control examination is still one of the best parameters to say whether the resection was complete or not, and to establish the presence of recurrence and/or residual lesions.

We can also highlight a good security profile using UEMR. Our findings show that bleeding occurred in $11.8 \%$ of cases. It is noteworthy that, of these, 5 (9.8\%) were minor and immediately controlled during the procedure; they should therefore not be viewed as an adverse event. We observed a similar rate of delayed bleeding (2\%) to Spadaccini et al (2.8\%) [32]. There were no cases of intestinal perforation in the study, a feared complication that has seldom been reported so far $[17,18,34]$. In contrast, some studies involving EMR describe bleeding values ranging from $2-11 \%$ and perforation rates around $1.5 \%$ [33,35-39]. Sánchez et al [40] believe that the safety profile offered by UEMR can be explained by the low probability of deep damage to the intestinal wall, due to the heat-sink effect of water. We particularly think that in the absence of the edema effect caused by injected solution, the post-resection mucosal defect is smaller and less deep using UEMR, which can facilitate the placement of endoscopic clips when needed.

This study had some limitations that should be highlighted. First, it was performed in a single tertiary center by 2 endoscopists experienced in EMR. Therefore, it is not known whether it can be reproduced in other institutions, despite the fact that the endoscopists who performed the procedures had not received any specific training in UEMR before the beginning of the study and just followed the technical details described in the literature. Secondly, the study sample was relatively small. Finally, patient follow up was inadequate, and thus long-term results such as recurrence rate could not be precisely assessed.

In conclusion, this study indicated that UEMR for the removal of adenomas and colorectal serrated lesions is feasible, safe and effective in clinical practice in Brazil. The technique may be included in the therapeutic arsenal of institutions that manage colorectal lesions, although further well-designed randomized controlled trials must be encouraged to support its generalized implementation, as well as to assess differences in lesion recurrence compared to EMR.

\section{Acknowledgment}

The authors would like to thank all members of the Department of Digestive Endoscopy at Hospital Madre Teresa, in particular the nursing team. 


\section{Summary Box}

\section{What is already known:}

- Endoscopic mucosal resection (EMR) with submucosal injection is a well-established and widely used technique that allows the removal of colorectal lesions of varying sizes

- Underwater EMR (UEMR) without submucosal injection has been described as an alternative technique and may prevent some issues related to EMR

\section{What the new findings are:}

- In this prospective observational study, UEMR for the removal of adenomas and colorectal serrated lesions was demonstrated to be feasible, safe and effective

- Future well-designed randomized controlled trials are needed to support its generalized implementation and to determine the best indications

\section{References}

1. Maruoka D, Arai M, Akizue N, et al. Residual adenoma after cold snare polypectomy for small colorectal adenomas: a prospective clinical study. Endoscopy 2018;50:693-700.

2. Repici A, Hassan C, Vitetta E, et al. Safety of cold polypectomy for $<10 \mathrm{~mm}$ polyps at colonoscopy: a prospective multicenter study. Endoscopy 2012;44:27-31.

3. Ferlitsch M, Moss A, Hassan C, et al. Colorectal polypectomy and endoscopic mucosal resection (EMR): European Society of Gastrointestinal Endoscopy (ESGE) Clinical Guideline. Endoscopy 2017;49:270-297.

4. Zauber AG, Winawer SJ, O’Brien MJ, et al. Colonoscopic polypectomy and long-term prevention of colorectal-cancer deaths. N Engl J Med 2012;366:687-696.

5. Hassan C, Quintero E, Dumonceau JM, et al; European Society of Gastrointestinal Endoscopy. Post-polypectomy colonoscopy surveillance: European Society of Gastrointestinal Endoscopy (ESGE) Guideline. Endoscopy 2013;45:842-851.

6. Schenck RJ, Jahann DA, Patrie JT, et al. Underwater endoscopic mucosal resection is associated with fewer recurrences and earlier curative resections compared to conventional endoscopic mucosal resection for large colorectal polyps. Surg Endosc 2017;31:4174-4183.

7. Burgess NG, Bahin FF, Bourke MJ. Colonic polypectomy (with videos). Gastrointest Endosc 2015;81:813-835.

8. Ahmad NA, Kochman ML, Long WB, Furth EE, Ginsberg GG. Efficacy, safety, and clinical outcomes of endoscopic mucosal resection: a study of 101 cases. Gastrointest Endosc 2002;55:390-396.

9. Binmoeller KF, Weilert F, Shah J, Bhat Y, Kane S. "Underwater" EMR without submucosal injection for large sessile colorectal polyps (with video). Gastrointest Endosc 2012;75:1086-1091.

10. Amato A, Radaelli F, Spinzi G. Underwater endoscopic mucosal resection: the third way for en bloc resection of colonic lesions? United European Gastroenterol J 2016;4:595-598.
11. Wang AY, Flynn MM, Patrie JT, et al. Underwater endoscopic mucosal resection of colorectal neoplasia is easily learned, efficacious, and safe. Surg Endosc 2014;28:1348-1354.

12. Curcio G, Granata A, Ligresti D, et al. Underwater colorectal EMR: remodeling endoscopic mucosal resection. Gastrointest Endosc 2015;81:1238-1242.

13. Cadoni S, Liggi M, Gallittu P, et al. Underwater endoscopic colorectal polyp resection: Feasibility in everyday clinical practice. United European Gastroenterol J 2018;6:454-462.

14. Uedo N, Nemeth A, Johansson GW, Toth E, Thorlacius H. Underwater endoscopic mucosal resection of large colorectal lesions. Endoscopy 2015;47:172-174.

15. Kim HG, Thosani N, Banerjee S, Chen A, Friedland S. Underwater endoscopic mucosal resection for recurrences after previous piecemeal resection of colorectal polyps (with video). Gastrointest Endosc 2014;80:1094-1102.

16. Siau K, Ishaq S, Cadoni S, Kuwai T, Yusuf A, Suzuki N. Feasibility and outcomes of underwater endoscopic mucosal resection for $\geq 10 \mathrm{~mm}$ colorectal polyps. Surg Endosc 2018;32:2656-2663.

17. Kawamura T, Sakai H, Ogawa T, et al. Feasibility of underwater endoscopic mucosal resection for colorectal lesions: a single center study in Japan. Gastroenterology Res 2018;11:274-279.

18. Chien HC, Uedo N, Hsieh PH. Comparison of underwater and conventional endoscopic mucosal resection for removing sessile colorectal polyps: a propensity-score matched cohort study. Endosc Int Open 2019;7:E1528-E1536.

19. Zarchy T. Risk of submucosal saline injection for colonic polypectomy. Gastrointest Endosc 1997;46:89-90.

20. The Paris endoscopic classification of superficial neoplastic lesions: esophagus, stomach, and colon: November 30 to December 1, 2002. Gastrointest Endosc 2003;58:S3-S43.

21. Kudo S, Hirota S, Nakajima T, et al. Colorectal tumours and pit pattern. J Clin Pathol 1994;47:880-885.

22. Burgess NG, Bassan MS, McLeod D, Williams SJ, Byth K, Bourke MJ. Deep mural injury and perforation after colonic endoscopic mucosal resection: a new classification and analysis of risk factors. Gut 2017;66:1779-1789.

23. Cotton PB, Eisen GM, Aabakken L, et al. A lexicon for endoscopic adverse events: report of an ASGE workshop. Gastrointest Endosc 2010;71:446-454.

24. Binmoeller KF, Hamerski CM, Shah JN, Bhat YM, Kane SD, Garcia-Kennedy R. Attempted underwater en bloc resection for large $(2-4 \mathrm{~cm})$ colorectal laterally spreading tumors (with video). Gastrointest Endosc 2015;81:713-718.

25. Cammarota G, Cesaro P, Cazzato A, et al. The water immersion technique is easy to learn for routine use during EGD for duodenal villous evaluation: a single-center 2-year experience. J Clin Gastroenterol 2009;43:244-248.

26. Hsieh YH, Binmoeller K, Leung FW. Underwater polypectomy: heat-sink effect in an experimental model. Gastrointest Endosc 2015;83:AB385.

27. Frossard JL, Gervaz P, Huber O. Water-immersion sigmoidoscopy to treat acute GI bleeding in the perioperative period after surgical colorectal anastomosis. Gastrointest Endosc 2010;71:167-170.

28. Binmoeller KF, Hamerski CM, Shah JN, Bhat YM, Kane SD. Underwater EMR of adenomas of the appendiceal orifice (with video). Gastrointest Endosc 2016;83:638-642.

29. Chaves DM, Brito HP, Chaves LT, Rodrigues RA, Sugai BM. Underwater endoscopic mucosal resection of serrated adenomas. Clinics (Sao Paolo) 2018;73:e339.

30. Chaves DM, Brito HP, Chaves LT, et al. Underwater endoscopic resection: an alternative for difficult colorectal polyps. VideoGIE 2016;1:82-84.

31. Yamashina T, Uedo N, Akasaka T, et al. Comparison of underwater vs conventional endoscopic mucosal resection of intermediate-size 
colorectal polyps. Gastroenterology 2019;157:451-461.

32. Spadaccini M, Fuccio L, Lamonaca L, et al. Underwater EMR for colorectal lesions: a systematic review with meta-analysis (with video). Gastrointest Endosc 2019;89:1109-1116.

33. Hassan C, Repici A, Sharma P, et al. Efficacy and safety of endoscopic resection of large colorectal polyps: a systematic review and meta-analysis. Gut 2016;65:806-820.

34. Ponugoti PL, Rex DK. Perforation during underwater EMR. Gastrointest Endosc 2016;84:543-544.

35. Arebi N, Swain D, Suzuki N, Fraser C, Price A, Saunders BP. Endoscopic mucosal resection of 161 cases of large sessile or flat colorectal polyps. Scand J Gastroenterol 2007;42:859-866.

36. Saito Y, Fukuzawa M, Matsuda T, et al. Clinical outcome of endoscopic submucosal dissection versus endoscopic mucosal resection of large colorectal tumors as determined by curative resection. Surg Endosc 2010;24:343-352.
37. Luigiano C, Consolo P, Scaffidi MG, et al. Endoscopic mucosal resection for large and giant sessile and flat colorectal polyps: a single-center experience with long-term follow-up. Endoscopy 2009;41:829-835.

38. Conio M, Repici A, Demarquay JF, Blanchi S, Dumas R, Filiberti R. EMR of large sessile colorectal polyps. Gastrointest Endosc 2004;60:234-241.

39. Burgess NG, Metz AJ, Williams SJ, et al. Risk factors for intraprocedural and clinically significant delayed bleeding after wide-field endoscopic mucosal resection of large colonic lesions. Clin Gastroenterol Hepatol 2014;12:651-661.e1-e3.

40. Rodríguez Sánchez J, Uchima Koecklin H, González López L, et al. Short and long-term outcomes of underwater EMR compared to the traditional procedure in the real clinical practice. Rev Esp Enferm Dig 2019;111:543-549. 